\title{
Levodopa Reduces Muscle Tone and Lower Extremity Tremor in Parkinson's Disease
}

\author{
Anne Burleigh, Fay Horak, John Nutt and James Frank
}

\begin{abstract}
Objective: We have quantified the effects of levodopa treatment in Parkinsonian subjects during maintained stance. Methods: Electromyographic muscle activity during quiet stance was assessed in subjects with Parkinson's disease, who exhibited a fluctuating response to levodopa, and in age-matched control subjects. Stance stability was also assessed from mean displacement and velocity of the center of pressure excursions during stance. Results: Lower extremity and trunk muscles showed high amplitude activity in all Parkinson's subjects when "off", and a 4-5 Hz tremor in three of these subjects. When "on", the amplitude of muscle activity was reduced in the distal muscles more than the proximal, while tremor was suppressed in all muscles. Corresponding to the excessive muscle activity, the Parkinson's subjects had increased velocity and variability of velocity in the anterior-posterior center of foot pressure excursions, but the mean displacement of the center of pressure excursion was not different from the controls. The velocity of center of pressure excursions in the Parkinson's subjects "on", approached those of the control subjects suggesting that the excessive distal muscle amplitude and tremor contributed to the high velocity of the center of pressure. Conclusions: These findings suggest that dopaminergic systems are involved in the regulation of muscle tone during stance. Depletion of dopaminergic transmission results in increased muscle tone and tremor in the lower extremities which may contribute to changes in posture and stability.
\end{abstract}

\begin{abstract}
RÉSUMÉ: La L-dopa diminue le tonus musculaire et le tremblement des membres inférieurs dans la maladie de Parkinson. Objectif: Nous avons quantifié les effets du traitement par la L-dopa chez des parkinsoniens en position debout. Méthodes: Nous avons évalué l'activité musculaire par électromyographie chez des parkinsoniens en position debout stable qui présentaient des fluctuations dans la réponse à la L-dopa et chez des sujets contrôles appariés pour l'âge. La stabilité de la posture était également évaluée par le déplacement moyen et la vélocité des oscillations du centre de pression pendant la station debout. Résultats: Les muscles des membres inférieurs et du tronc présentaient une activité de haute amplitude chez tous les parkinsoniens quand ils n'étaient pas sous l'effet de la L-dopa et un tremblement de $4-5 \mathrm{~Hz}$ chez trois de ces sujets. Quand ils étaient sous l'effet du médicament, l'amplitude de l'activité musculaire était diminuée de façon plus marquée dans les muscles distaux que proximaux, alors que le tremblement était supprimé dans tous les muscles. Les parkinsoniens présentaient un accroissement de la vélocité et de la variabilité de la vélocité des oscillations antéro-postérieures du centre de pression du pied correspondant à l'activité musculaire excessive, mais le déplacement moyen du centre de pression n'était pas différent de celui des contrôles. La vélocité des oscillations du centre de pression chez les parkinsoniens en période d'effet de la L-dopa était presque identique à celle des contrôles, suggérant que l'amplitude excessive des muscles distaux et le tremblement contribuaient à la haute vélocité du centre de pression. Conclusions: Ces observations suggèrent que les systèmes dopaminergiques sont impliqués dans la régulation du tonus musculaire pendant la station debout. L'épuisement de la transmission dopaminergique mène à l'augmentation du tonus musculaire et au tremblement des membres inférieurs, ce qui peut contribuer aux changements dans la posture et la stabilité.
\end{abstract}

Can. J. Neurol. Sci. 1995; 22: 280-285

Parkinson's disease (PD) is characterized clinically by resting tremor, muscle rigidity, bradykinesia and disturbed postural responses.' These motor disturbances are related to loss of dopamine in the nigrostriatal system. Treatment with the dopamine precursor, levodopa (L-dopa) typically improves the motor performance of persons with PD. Although there is evidence that L-dopa is more effective in treating limb dysfunction than axial symptoms, ${ }^{2,3}$ quantification of the effects of L-dopa on muscle activity and stability during stance is lacking. We have quantified the effects of L-dopa treatment on the baseline muscle activity and tremor in lower extremity and trunk muscles,

From the R.S. Dow Neurological Sciences Institute of GSH \& MC (A.B., F.H.); the Departments of Physiology (A.B., F.H.), and Neurology (F.H., J.N.) at Oregon Health Sciences University, Portland, Oregon; the Department of Kinesiology (J.F.) at University of Waterloo, Waterloo, Ontario.

RECEIVED JANUARY 2, 1995. ACCEPTED IN FINAL FORM MARCH 29, 1995.

Reprint requests to: Fay Horak, R.S. Dow Neurological Science Institute, 1120 N.W. 20th Avenue, Portland OR 97209-1595 USA. 
and on stance stability as assessed from mean displacement and velocity of the center of pressure excursions during stance.

\section{MethodS}

Eleven subjects ( 6 male, 5 female; age 61.6 y \pm 4.5 ) with idiopathic Parkinson's disease (Hoehn and Yahr stages III to IV when "off") and eleven neurologically normal, age-matched controls participated in the study. The mean duration of disease in the subjects with Parkinson's disease was 13 years, ranging from 6 to 35 years. Three PD subjects had clinically apparent tremor in both hands. Subjects with PD reported to the laboratory in the morning, having withheld their morning L-dopa/carbidopa (Sinemet ${ }^{\otimes}$ ), and were initially tested when "off" (i.e., off medication and parkinsonian features prominent). Subjects then took their normal L-dopa dose and were re-tested approximately one hour later when "on" (i.e., on medication and parkinsonian features diminished). During the testing sessions, subjects stood comfortably on a dual-plate platform, with one foot centered on each plate, arms folded in front of the body and gaze directed forward to the laboratory wall. Subjects had come to the laboratory to participate in another experiment, thus the data being presented in this paper result from single trials recorded for three seconds as a baseline measure of independent stance. All subjects were able to stand independently for longer than the reported three second interval. Two subjects with PD later returned for repeat testing, to verify the repeatability of the results.

Surface electrodes were used to record electromyographic activity (EMGs) unilaterally from the tibialis anterior, medial gastrocnemius, rectus femoris, biceps femoris, and paraspinals. Skin impedance was less than $15 \mathrm{KOhms}$ for all subjects, with electrodes kept in place throughout the entire period of testing. The EMGs were amplified, band-pass filtered $(70-2000 \mathrm{~Hz})$ and full-wave rectified. The mean amplitude and standard deviation of muscle activity during quiet stance over the full 3 second period was quantified using a Macintosh program (Axograph) for wave analysis. The mean amplitude and standard deviation of one second intervals over the full period was also quantified to verify that the mean EMG level was stable over the $3 \mathrm{sec}-$ onds. Fourier analysis of the individual muscle EMGs over the three seconds was used to determine the presence and frequency of tremor.

Surface forces were recorded using strain gauges mounted in the platform, and the anterior-posterior displacement of the center of foot pressure (COP) was calculated for the full $3 \mathrm{sec}-$ ond period. The velocity of COP was calculated as the first derivative of the filtered COP displacement data. The mean anterior and mean posterior excursion of the COP and the pathlength over time were quantified to determine if the amount of sway was greater in the PD subjects compared to the controls. Both anterior and posterior excursions were expressed as positive change with respect to foot center. This allowed the mean amplitude of excursion about baseline to be quantified. The COP velocity data was rectified and the mean and standard deviation of the velocity were quantified. Velocity was therefore expressed as a positive value of mean rate of change of the COP with respect to the foot center. Increases in the velocity parameters correspond to decreases in stance stability. ${ }^{4}$ Information from the excursion and velocity of excursion of the
$\mathrm{COP}^{4.5}$ thus provided a measure of stability that could be directly compared across Parkinson's and control subjects. A Fourier analysis of the COP displacement data was used to determine if tremor was solely responsible for differences in the velocity parameters between the PD and control subjects.

A paired Student's t-test was used to compare mean EMG amplitude between PD subjects "off" and "on". Paired t-tests were also used to compare mean amplitude of excursion, mean velocity, and mean pathlength of COP between PD subjects "off" and "on". An unpaired t-test was used to compare mean amplitude of excursion, mean velocity, and mean pathlength of COP between PD subjects and control subjects. A p-value of less than 0.05 was accepted for statistical significance. A coefficient of variation for the COP velocity was calculated for each subject group to control for differences as the mean velocity increased.

\section{RESULTS}

When "off", the EMG activity of the PD subjects was excessive in all muscles recorded during quiet stance. High phasic activity and spiking of the EMG activity was a common feature in all PD subjects, but was not seen in control subjects, as illustrated by the representative PD and control subjects in Figure 1 . A Fourier transform revealed multiple frequency components in EMG's of three PD subjects (Figure lB). Administration of Ldopa resulted in significant reduction of excess amplitude in the distal lower extremity muscles but not the proximal lower extremity muscles or paraspinals. L-dopa did not significantly change the frequency components of the EMG. When "on", the mean amplitude of the tibialis and gastrocnemius was significantly reduced $(p \leq 0.01)$ in the PD subjects with the administration of L-dopa (Figure 2), however, the spike-like firing pattern persisted. There was no significant reduction in the mean amplitude of the more proximal rectus femoris, biceps femoris, or paraspinal muscles, but there was a trend for EMG amplitude in these muscles to decrease after the administration of L-dopa (Figures 1 and 2). The mean percent reduction in EMG activity was $46.3 \pm 16.25 \%$ for tibialis $(p \leq 0.01)$, and $30.3 \pm 16.25 \%$ for gastrocnemius ( $p \leq 0.01$ ), but only $1.42 \pm 4.2 \%$ for the rectus femoris (ns), $25.27 \pm 17.54 \%$ for biceps femoris (ns), and 12.92 $\pm 4.87 \%$ for paraspinals (ns). There was no correlation between disease severity or duration and the percent reduction in the EMG amplitudes quantified in the PD subjects when "on". Although a direct comparison of EMG amplitudes between control and PD subjects is not possible, the mean amplitude of EMGs for the group of PD subjects "off" far exceeded EMG amplitudes recorded in control subjects with similar electrode placement and impedance (Figure 2). Also, the phasic, spikelike firing pattern was unique to the PD subjects since it was never observed in the control subjects. Administration of L-dopa reduced mean EMG in the PD subjects "on", with levels approaching those measured in control subjects. The effect was reproducible as indicated by a similar reduction of distal muscle activity seen in the two Parkinson's subjects who returned to the laboratory for repeat testing. Furthermore, analysis of one second intervals in all subjects confirmed that the muscle activity remained stable over the full three seconds since there was no difference between the values obtained for the one second intervals and the full three second period. 


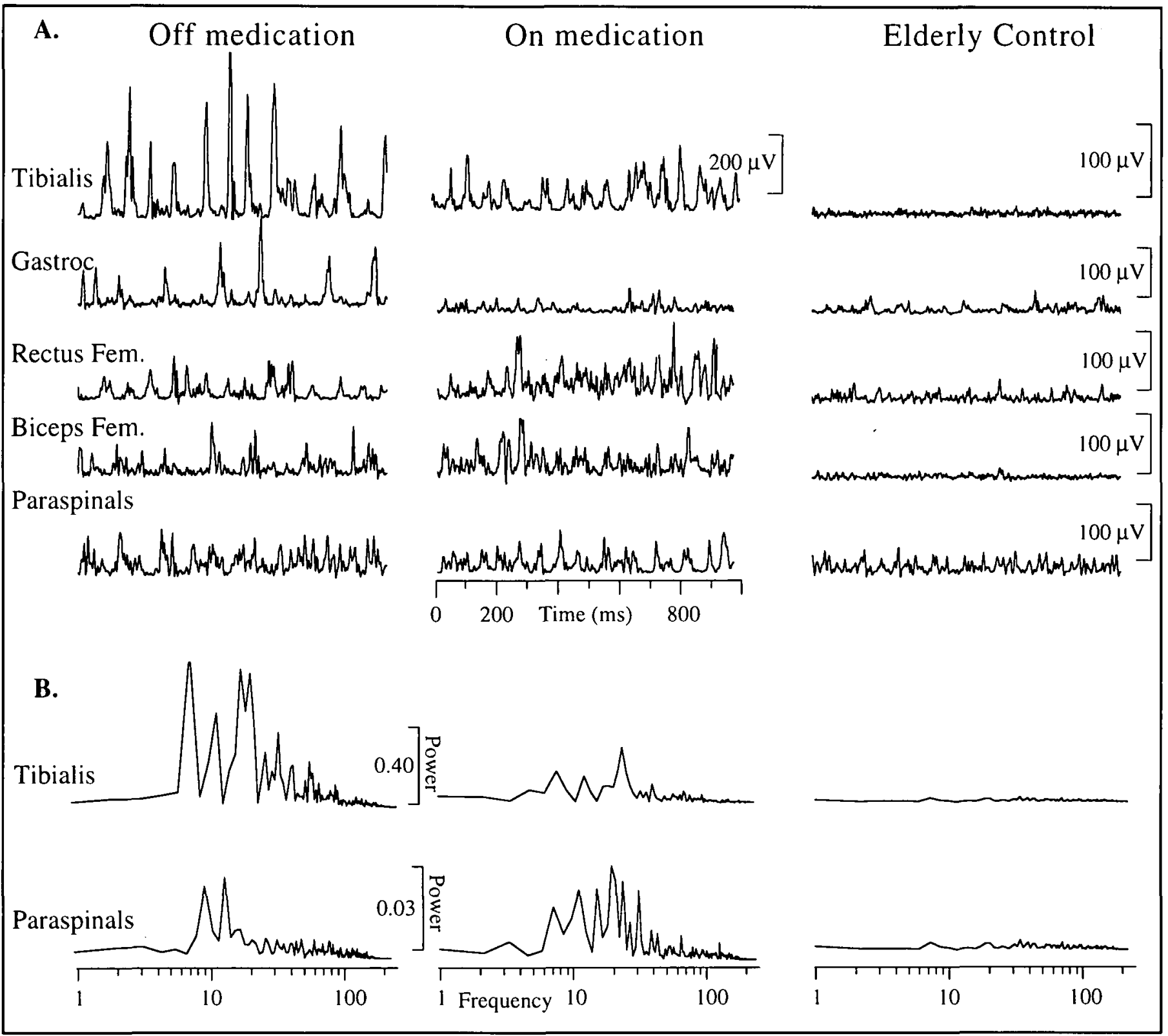

Figure I: (A) EMG activity recorded from a Parkinson's subject off and on L-dopa medication and an elderly contml subject during quiet stance. The PD subject exhibits high tonic activity in all muscles. Only the tibialis and gastrocnemius activity is clearly reduced with L-dopa medication. The $200 \mu V$ calibration applies to the tibialis EMG for the PD subject; all other calibration bars apply to the PD and control subject EMGs. (B) Corresponding Fourier analysis of the tibialis and parqaspinal EMGs demonstrating multiple high-frequency components in the PD subject, that are not affected by $L$-dopa.

In addition to high amplitude activity, three PD subjects also exhibited a distinct $4-5 \mathrm{~Hz}$ tremor in the lower extremity muscles and paraspinals. Although not apparent on clinical examination, the tremor was in all muscles recorded in two subjects, while in the third, tremor was recorded only from the tibialis and rectus femoris. Administration of L-dopa suppressed the tremor activity in all lower extremity muscles and the paraspinals, but reduced the mean amplitude of tonic EMG activity only in the tibialis and gastrocnemius (Figure 3).

Analysis of the COP suggested that the high amplitude and phasic muscle activity in the PD subjects contributed to a faster and less predictable excursion of the body during stance. The mean amplitude of the COP in the PD subjects was not significantly dif- ferent from controls (Figure 4A), thus, the PD subjects did not exhibit a larger amplitude sway than the controls during stance. However, both the mean velocity of the COP excursion (Figure 4B) and the standard deviation of the velocity were significantly greater in the PD subjects "off" compared to controls ( $p \leq 0.02)$ and the PD subjects "on" compared to controls ( $\mathrm{p} \leq 0.05$ ), (Table). When 'off', the velocity measures of the PD subjects were almost 10 times greater than controls, even though the amplitude of the COP excursion was not significantly different. Corresponding to the higher velocity without increases in the amplitude of COP excursion, the mean pathlength was significantly greater in the PD subjects "off" compared to controls ( $\mathrm{p} \leq 0.02$ ) and the PD subjects "on" compared to controls ( $\mathrm{p} \leq 0.05$ ), 


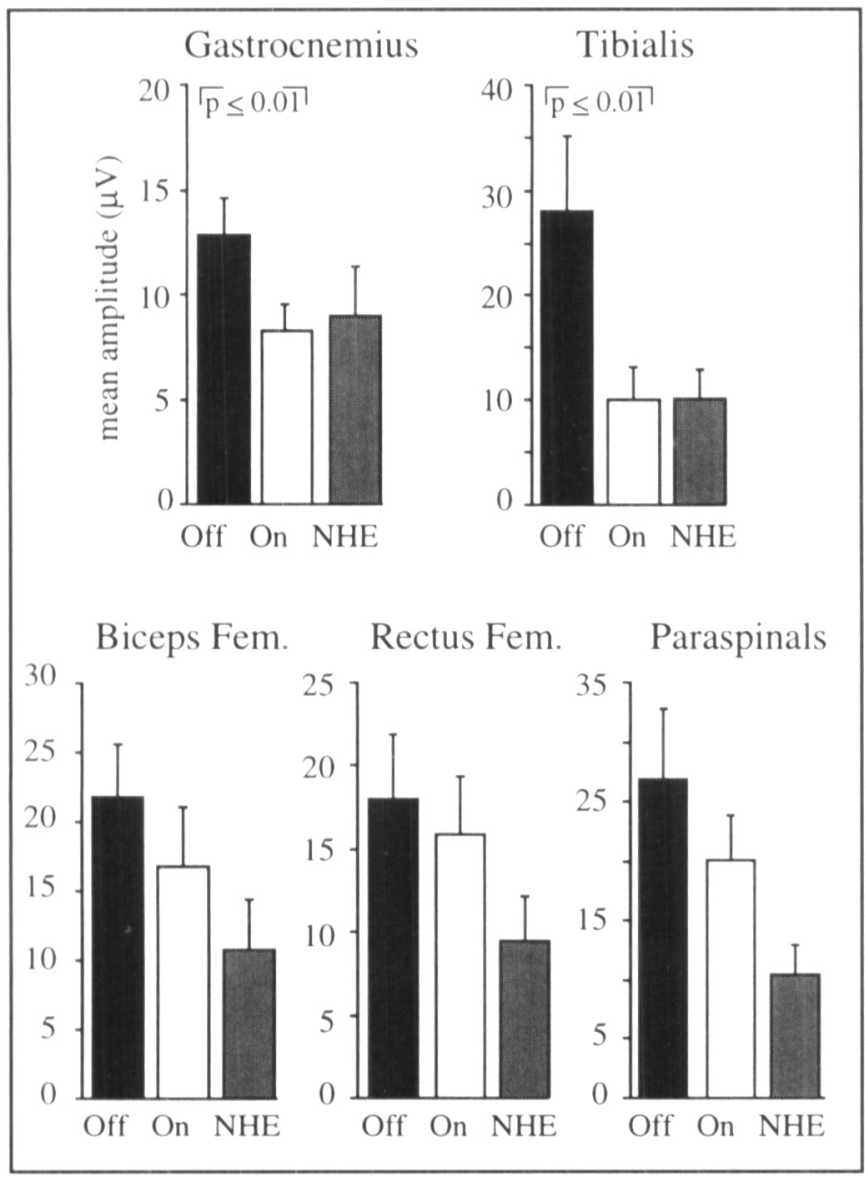

Figure 2: Mean amplitude and standard error of EMG activity recorded in eleven Parkinson's subjects off L-dopa medication (Off = black bar) and on medication (On = clear bar), and Normal Healthy Elderly. controls (NHE = gray bar). When "on", a significant reduction $(p \leq$ 0.01 ) of tibialis and gastrocnemius activity in the PD subjects was verified with a Student's t-test and EMG amplitudes approached those measured in NHE. L-dopa did not significantly reduce pmoximal muscle tone in PD subjects. No statistical comparison can be made between $E M G$ amplitudes of PD subjects and the control subjects, however; the mean values demonstrate that tonic activity is consistently higher in the PD subjects "off" and approaches control values when "on".

(Table). To verify that the significant differences in the standard deviation of velocity were not due only to increases in the mean, a coefficient of variation was calculated, with differences still existing between the PD subjects and controls (percent variability with respect to mean; control $=60 \%$, off $=119 \%$, on $=$ $101 \%$ ). When "on", all PD subjects showed a reduction in the velocity of the COP excursion, and the group mean approached that of the controls. Five PD subjects, when "on", had velocity measures within the normal control range.

\section{Discussion}

Two distinct observations have been presented with respect to the effects of oral L-dopa on postural mechanisms in Parkinson's disease. First, PD subjects exhibit excessively high amplitude, phasic activity in lower extremity and trunk muscles which is significantly reduced in the distal but not proximal lower extremity and trunk muscles by administration of L-dopa. Second, the 4-5 Hz tremor in lower extremity and trunk muscles during stance was abolished by L-dopa, while $8-20 \mathrm{~Hz}$

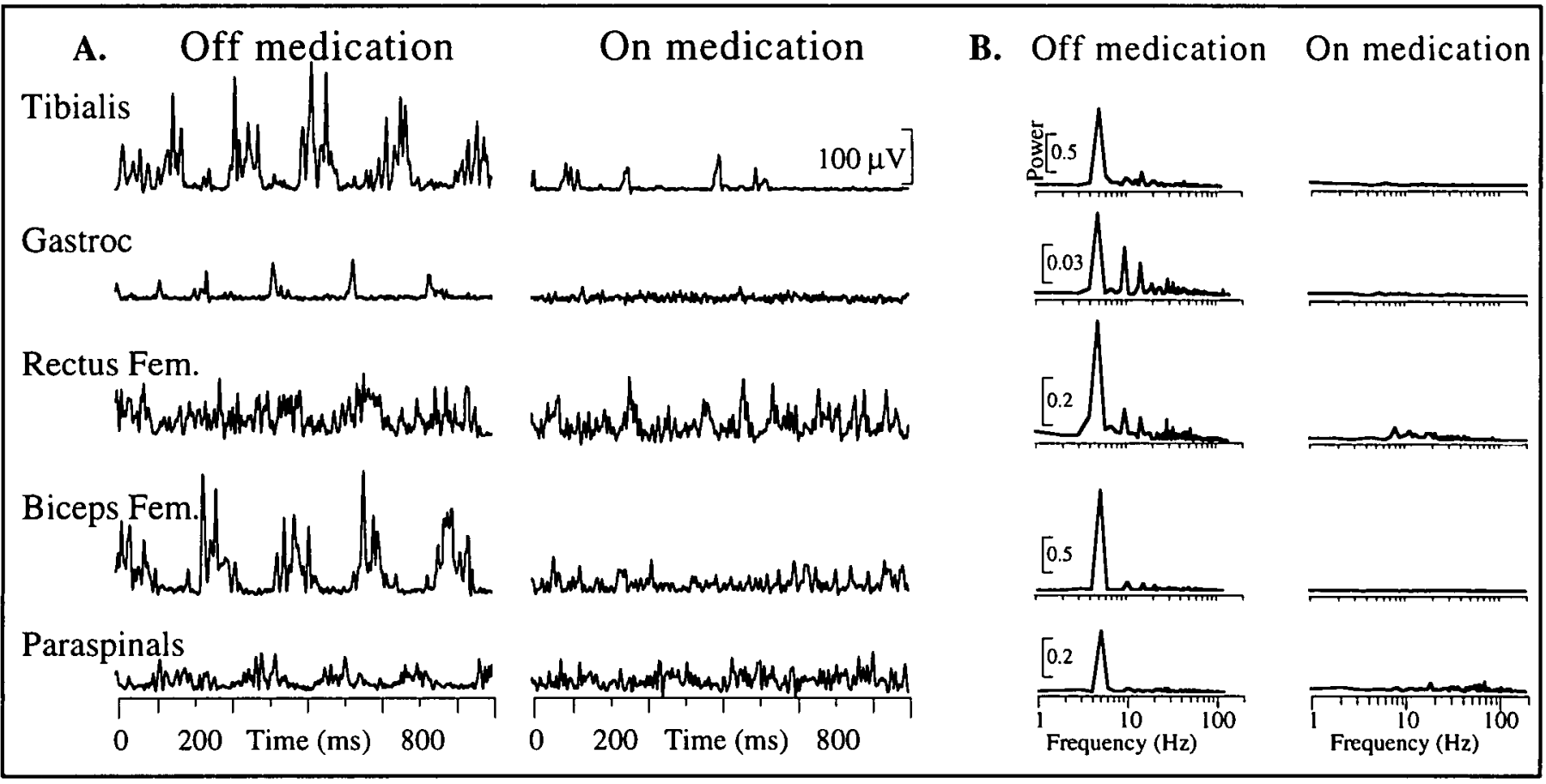

Figure 3: (A) EMG activity recorded from a Parkinson's subject off and on L-dopa medication during quiet stance; (B) corresponding Fourier analysis of the EMG. A $4-5 \mathrm{~Hz}$ tremor is present in all muscles when "off", but suppressed when "on". The $100 \mu \mathrm{V}$ calibration bar applies to all muscles. 


\begin{tabular}{lcccc}
\hline \multicolumn{5}{l}{ Table: Center of Pressure Measures and Significance. } \\
\hline Group & $\begin{array}{l}\text { Amplitude } \\
(\mathbf{c m})\end{array}$ & S.D. of Amp. & $\begin{array}{l}\text { Velocity } \\
\text { (cm/s) }\end{array}$ & $\begin{array}{l}\text { Pathlength } \\
\text { (cm) }\end{array}$ \\
\hline OFF & 1.12 & 0.68 & 9.65 & 31.11 \\
& $(1.22)$ & $(0.75)$ & $(10.84)$ & $(34.46)$ \\
ON & 1.26 & 0.76 & 6.56 & 16.89 \\
& $(1.14)$ & $(0.77)$ & $(9.61)$ & $(19.34)$ \\
NHE & 0.93 & 0.26 & 1.08 & 2.98 \\
& $(1.88)$ & $(0.23)$ & $(0.61)$ & $(1.90)$ \\
Off vs. On & $\mathrm{ns}$ & $\mathrm{ns}$ & $\mathrm{ns}$ & $\mathrm{ns}$ \\
Off vs. NHE & $\mathrm{ns}$ & $\mathrm{ns}$ & $\mathrm{p}<0.02$ & $\mathrm{p}<0.02$ \\
On vs. NHE & $\mathrm{ns}$ & $\mathrm{ns}$ & $\mathrm{p}<0.05$ & $\mathrm{p}<0.05$ \\
\hline
\end{tabular}

NHE $=$ elderly controls, $\mathrm{OFF}=$ Parkinson's subjects off L-dopa medication, $\mathrm{ON}=$ Parkinson's subjects on L-dopa medication. Measures are expressed as group means and (standard deviations).

components of phasic activity were unaffected by L-dopa. These observations suggest that dopaminergic systems, in part, regulate motor neuron activity for muscle tone during stance. ${ }^{6}$ The increased muscle activity corresponds to an increased variability in the velocity of the anterior-posterior COP excursion for all PD subjects. Although the PD subjects do not exhibit a larger excursion of the COP during stance, the velocity is faster and less predictable. These findings are consistent with the notion that a stiff system oscillates faster about a point of equilibrium. The increased variability in the velocity measures may represent a disruption in a constant control signal for maintenance of stance stability. Whether the baseline activity of the muscles contributes to the instability or is a result of instability is uncertain, but the abnormal spike-like EMG and tremor activity in the PD subjects suggests that the muscle activation contributes to the instability. The flexed-posture common in PD, may contribute to the excess muscle activity, however, when normal subjects stand in a similar flexed-posture, excessive muscle activity is not observed.

The output projections of the basal ganglia are somatotopically organized primarily from the internal globus pallidus and substantia nigra pars reticulata to the thalamus and the pedunculopontine tegmental region of the brainstem. ${ }^{7}$ We propose that there may exist descending brainstem projections involved in the regulation of postural muscle tone; while thalamocorticalspinal projections with a dopaminergic dependence may be involved regulation of distal muscle tone and the $4-5 \mathrm{~Hz}$ tremor generation.

\section{A. Anterior-posterior COP excursion}
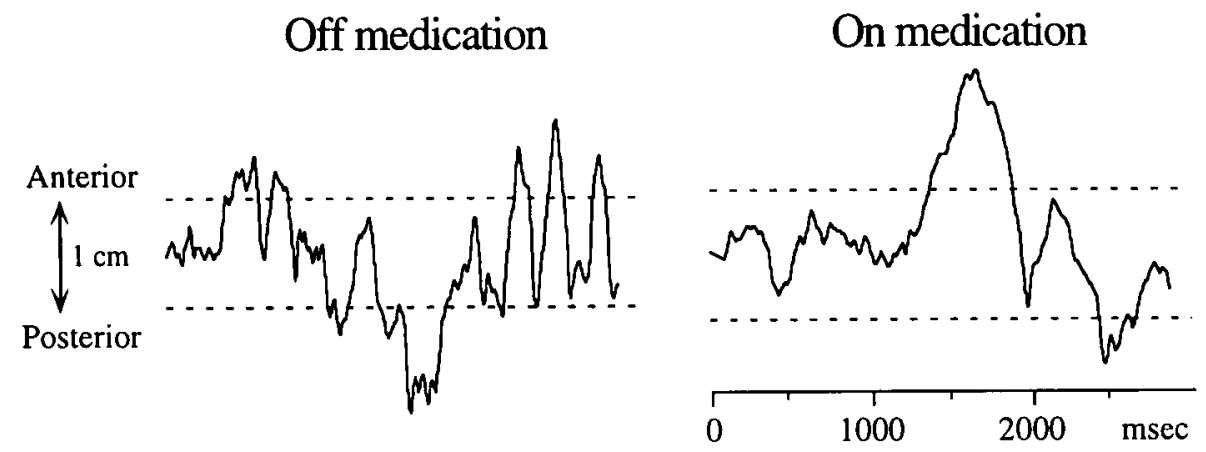

\section{B. Velocity of anterior-posterior COP excursion}

\section{Off medication}

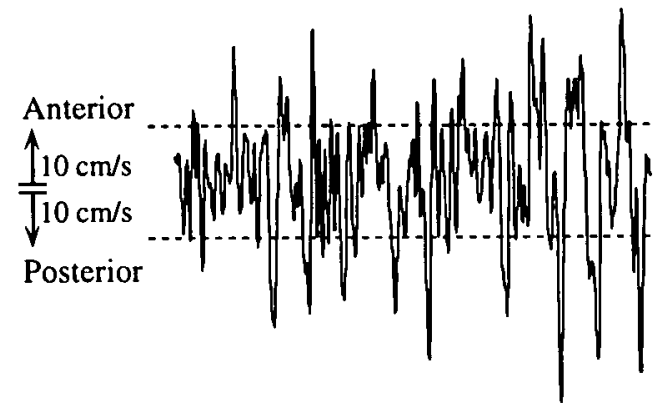

On medication

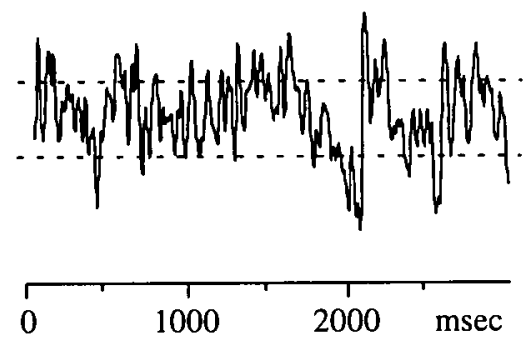

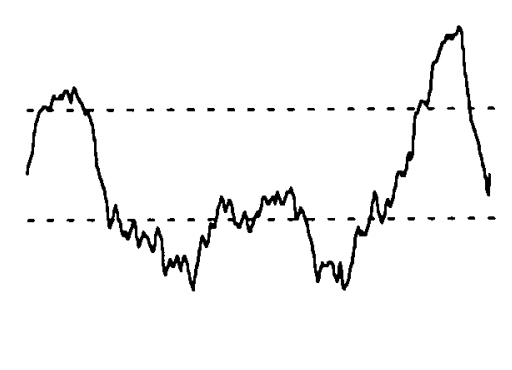

Elderly Control

Figure 4: (A) Anterior-posterior COP recorded from a Parkinson's subject off and on L-dopa medication and an elderly control subject during quiet stance. The dashed lines indicate the mean amplitude of excursion from anterior to posterior which is not significantly different between the PD and control subjects. $(B)$ Corresponding velocity of the COP. The dashed lines indicate the mean velocity of the anterior excursion and the posterior excursion which is significantly greater in the PD subjects compared to the control. 
Support for the role of a dopaminergic influence on distal limb muscle tone comes from both animal and human studies. Increases in distal muscle tone following disruption of the dopaminergic system of the BG have been previously quantified in animal models of PD including the MPTP treated primates ${ }^{8}$ and monoamine depleted ${ }^{8}$ or 6-hydroxydopamine (6-OHDA) lesioned rats. ${ }^{9} \mathrm{EMG}$ activity of the gastrocnemius and tibialis is increased when dopaminergic transmission is reduced. ${ }^{9}$ Although these animal studies have not quantified changes in proximal muscles, they do suggest that the dopaminergic system of the BG plays a critical role in the regulation of muscle tone. Administration of L-dopa in PD patients has been demonstrated to increase distal arm movement velocity more than axial movement velocity, ${ }^{2}$ further suggesting a stronger dopaminergic influence on the more distal muscles.

In the cat, the BG and the tegmental regions of brainstem have been demonstrated to be critical in the setting of hind limb postural tone for standing prior to locomotion. ${ }^{10,11}$ These studies suggest that BG projections to brainstem pathways may contribute to regulation of stance and locomotion, however no specific involvement of the dopaminergic system has been quantified.

Because thalamic stimulation can be effective in reducing both arm and postural muscle tremor in PD patients, ${ }^{12}$ the thalamocortical and corticospinal pathways may be involved in the pathophysiology of the $4-5 \mathrm{~Hz}$ tremor during standing. Lower extremity tremor of $4-5 \mathrm{~Hz}$ during standing has been previously reported in early PD, but considered a variant of orthostatic tremor appearing as an initial symptom of $\mathrm{PD} .{ }^{13}$ The clinical features of orthostatic tremor, however include a $10-16 \mathrm{~Hz}$ tremor in the leg muscles during standing that disappears with walking or sitting. ${ }^{14}$ The $4-5 \mathrm{~Hz}$ tremor in postural muscles reported in this study as well as previously reported from our laboratory, ${ }^{12}$ indicates that lower extremity tremor may be a more common characteristic of PD than previously recognized. Interestingly, this tremor activity persisted during postural adjustments to surface displacements and during a voluntary rise to toes task. ${ }^{6}$

In contrast to the $4-5 \mathrm{~Hz}$ tremor, the higher frequency components of EMG activity seen in three different PD subjects in this study are not affected by L-dopa administration. The general spike-like behaviour of the EMG in the PD subjects may be reflective of basal ganglia influence on spinal circuitry, including decreased sensitivity of polysynaptic reflex pathways and increased recurrent and reciprocal inhibition. ${ }^{15.16}$ Further experimentation is necessary to differentiate the mechanisms involved in the abnormal regulation of muscle tone.

In conclusion, our findings offer some quantification for the observation of increased postural muscle tone and lower extremity tremor in Parkinson's disease, which is partially reduced by
L-dopa. Quantification of the velocity parameters of the COP provides a tool to discriminate postural stability which may be related to high amplitude, phasic muscle activity during stance.

\section{ACKNOWLEDGEMENTS}

We thank our subjects who so willingly participated in this study. This research was supported by a grant from the National Institute on Aging (AGO-6457) awarded to Fay Horak, and a grant from the Foundation for Physical Therapy awarded to Anne Burleigh.

\section{REFERENCES}

1. Marsden CD. Defects of movement in Parkinson's disease. In: Delwaide PJ, Agnoli A, eds. Clinical Neurophysiology in Parkinsonism. Elsevier Science Pub. (Biomed Division) 1985; 107-115.

2. Weinrich M, Koch K, Fernando-Garcia AB, Angel RW. Axial versus distal motor impairment in Parkinson's disease. Neurology 1988; 38: 540-545.

3. Klawans HL. Individual manifestations of Parkinson's disease after 10 or more years of levadopa. Mov Disord 1986; 1: 187-192.

4. Riley PO, Benda BJ, Gill-Body KM, Krebs DE. Phase plane analysis of stability in quiet standing. J Rehab Res Develop 1995; (in press).

5. Hlavacka F, Saling M. Compensation effect of visual feedback in upright posture control. Activ. Nerv. Sup. 1986; 28(3): 191. 196.

6. Horak FB, Frank J. Three separate postural systems affected in Parkinsonism. In: Stuart DG, Gurfinkel VS, Weisendanger M, eds. Motor Control VII: Proceedings of the VIlth Symposium on Motor Control. Tuscon: Motor Control Press, 1995.

7. Hallett M. Physiology of basal ganglia disorders: an overview. Can J Neurol Sci 1993; 20: 177-183.

8. Klockgether T, Turski L, Honore' T, et al. The AMPA receptor antagonist NBQX has antiparkinsonian effects on monoamine depleted rats and MPTP-treated monkeys. Ann Neurol 1991; 30: 717-723.

9. Double KL, Crocker AD. Quantitative electromyographic changes following modification of central dopaminergic transmission. Brain Res 1993; 604: 342-344.

10. Garcia-Rill E. The basal ganglia and the locomotor region. Brain Res Rev 1986; 11: 47-63.

11. Mori S. Contribution of postural muscle tone to full expression of posture and locomotor movements: multi-faceted analyses of its setting brainstem-spinal cord mechanisms in the cat. Jap J Physiol 1989; 38: 785-809.

12. Burleigh AL, Horak FB, Burchiel KJ, Nutt JG. Effects of thalamic stimulation on tremor, balance, and step-initiation: a single subject study. Mov Disord 1993; 8(4): 519-524.

13. Kim JS, Lee MC. Leg tremor mimicking orthostatic tremor as an initial manifestation of Parkinson's disease [letter]. Mov Disord 1993; 8(3): 397-398.

14. Thompson PD, Rothwell JC, Day BL, et al. The physiology of orthostatic tremor. Arch Neurol 1986; 43: 584-587.

15. Obeso JA, Quesada P, Artieda J, Martinez-Lage JM. In: Delwaide PJ, Agnoli A, eds. Clinical Neurophysiology in Parkinsonism. Elsevier Science Pub. (Biomed Division) 1985; 9-18.

16. Lelli S, Panizza M, Hallett M. Spinal cord inhibitory mechanisms in Parkinson's disease. Neurology 1991; 41: 553-556. 